\title{
SOBRE A DINÂMICA DA IDEOLOGIA À LUZ DA INTERPRETAÇÃO LUKÁCSIANA
}

\author{
Nara Roberta Silva
}

\begin{abstract}
RESUMO
Reconhecendo que o conceito de ideologia apresenta uma gama de significados, acepções e definições, o artigo procura debatê-lo no contexto da leitura de György Lukács - considerando que não há uma concepção de ideologia sistematizada pelo próprio Karl Marx. Com isso, parte-se da relação não dicotômica entre realidade objetiva e subjetividade visualizada através do trabalho, cerne da teoria marxiana, e define-se ideologia a partir de sua função social de intervir nos conflitos, impasses e questões de cunho também social. Em decorrência, considerando seu caráter de consciência eminentemente prática, exploram-se então aspectos concernentes à complexa dinâmica da ideologia, que possibilitam compreender sua atuação e sua influência em meio a uma dada formação social - dinâmica esta sintetizada no que optamos por chamar de linguagem da evidência.
\end{abstract}

Palavras-chave: Ideologia. Marxismo. Ontologia. Lukács.

\section{ON THE DYNAMICS OF IDEOLOGY ACCORDING TO LUKÁCS' PERSPECTIVE}

\begin{abstract}
Regarding that the concept of ideology has a range of meanings, this article aims to present it through the György Lukács' interpretation of Marx's work - considering that there is no ideology conception systematized by Marx himself. As a starting point, labor is considered the core of the Marxian theory and the reason of an intimate

Doutoranda em Sociologia pela Universidade Estadual de Campinas, Brasil. nararoberta@gmail.com
\end{abstract}


relation between objective reality and subjectivity. It is then possible to define ideology by its social function to intervene upon social conflicts, impasses, and dilemmas, and show how such kind of representation presents a very practical feature. As a further step, it is necessary to understand the way ideology operates and potentially influences society. This means introducing its particular dynamics, which unfolds throughout different but concurrent levels. Here I name such dynamics evidence language.

Palavras-chave: Ideology. Marxism. Ontology. Lukács.

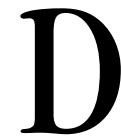
esde 0 uso inicial do termo pelo grupo de filósofos ligado a Destutt de Tracy, na França da virada do século XVIII para o século XIX, ideologia é alvo de inúmeros debates e controvérsias. A enorme variedade de significados que o termo paulatinamente adquiriu até os dias de hoje tornaram 0 conceito de ideologia um dos mais polêmicos e contenciosos no âmbito das ciências sociais e das ciências humanas em geral, evidenciando o quanto 0 debate é perpassado por aspectos práticos e políticos.

Tanto o mar de sentidos, acepções e definições em que está imerso o termo e, por conseguinte, o conceito, quanto as inevitáveis consequências práticas que 0 envolvem tornam bastante difícil a tarefa de debater a temática da ideologia. A despeito disso, a referida multiplicidade de significados facilmente revela que grande parte das formulações - senão todas - sobre ideologia emergentes ao longo do século XX e início do século XXI tem como interlocutor as proposições de Karl Marx - em maior ou menor medida (SILVA, 2012, p. 15-24). Mais especificamente, diversos autores preocuparam-se em ratificar ou retificar o que foi posto por Marx - juntamente com Engels - n'A ideologia alemã, procurando ou aprofundar e refinar as proposições tecidas a partir da crítica aos jovens hegelianos de esquerda ou então modificá-las, parcial ou totalmente. No fim, o que é visto como a posição de Marx acerca da questão da ideologia exerceu (e exerce) forte influência sobre outros autores, das mais diversas filiações teóricas.

A despeito de tal influência, é possível afirmar que, curiosamente, não há uma concepção de ideologia sistematizada pelo próprio Marx (RANIERI, 2003, p. 20). De fato, ideologia está sim presente por vezes de forma destacada em certos escritos marxianos. Contudo, ainda que as relevantes anotações acerca do fenômeno ideológico ao longo da obra de Marx sejam importantes indicações por ele deixadas, não foram elas nem organizadas e nem esclarecidas a fundo - da mesma forma que ocorre, por exemplo, com a questão do Estado, das classes sociais e do método. Como resultado, é questionável uma caracterização marxiana 
da ideologia unicamente como falsa consciência ou como consciência invertida da realidade social. Internamente a essa perspectiva, subsistem decerto diversos vieses quanto ao traço de falsidade - mais ou menos epistêmica, mais ou menos funcional. No entanto, cabe notar que sua prevalência quando à interpretação das propostas marxianas, mesmo que distintamente, se coloca para teóricos contrários e também para teóricos próximos ao materialismo histórico.

Frente à alegada influência de Marx no debate sobre ideologia e à ausência de uma posição comum também internamente à própria teoria marxista acerca dos contornos típicos deste fenômeno, a retomada das preciosas indicações deixadas abre a possibilidade de que se amplie a compreensão das propostas marxianas relativas a tão polêmico tema. Tal esforço não é inédito no campo da teoria marxista e importantes autores promoveram discussões acerca do conceito de ideologia, reconhecendo de maneira explícita ou não a ausência de sistematização à qual aludimos acima. Como exemplos, pode-se citar Louis Althusser (1999), que distinguiu a ideologia como um concomitante processo de alusão e ilusão da realidade, respaldado por diversos aparelhos - aparelhos ideológicos - então presentes na sociedade, e Antonio Gramsci (1999), o qual deixa antever, no meio de suas extensas anotações, a contribuição da ideologia para a guerra de posição, na medida em que pode contribuir para a tomada de consciência e para o conhecimento de uma classe social em luta.

Ao construírem suas propostas, os autores supracitados terminam por confirmar que, apesar da ausência de sistematização, há um nível superior de elaboração da questão da ideologia por Marx, já que ela não se reduz a um leque de definições ou um traçado de características - diferentemente, a reflexão marxiana traz consigo mais do que meros aspectos da ideologia, potencialmente encaminhando-se, na verdade, para a elucidação do arranjo típico da reprodução social, especialmente na sociedade capitalista. Para falar de ideologia em Marx, é preciso atentar, portanto, que ele nos dá como legado um sistema teórico intimamente interligado, de modo que, para compreendermos o que diz respeito à ideologia, deve-se ter em conta toda a organização deste edifício conceitual dentro do qual o fenômeno se insere.

Consequentemente, o modo como se concebe o sistema teórico marxiano desempenha papel fundamental nos contornos a serem então adquiridos pelo conceito em questão. No caso do presente texto, a exposição desenrolar-se-á através da perspectiva de György Lukács - o qual, em seu período de maturidade, pontuou a orientação ontológica da obra de Marx. Com base em Lukács, não nos preocupamos então com qualquer tipo de reformulação do conceito - na verdade, 
nosso objetivo é, antes de tudo, apresentar o que é e o que concerne à ideologia, tendo em vista a dificuldade em se trabalhar com a perspectiva marxiana. Todavia, considerando o dito até aqui, defendemos que, certamente, entender o que é e 0 que concerne à ideologia está relacionado a compreender sua atuação decisiva internamente à realidade social. Consequentemente, os esforços para explorar as indicações de Marx em busca do significado atribuído ao conceito em questão completam-se, a nosso ver, com o delineamento da complexa dinâmica da qual é dotado o fenômeno ideológico. Com isso, nota-se que, embora não se pretenda a reformulação do conceito de ideologia, não se procura apresentar, ao longo das páginas a seguir, uma exegese dos escritos lukácsianos e sim desenvolver as ideias ali contidas, na medida em que as consideramos mais pertinentes para responder à indagação de como a ideologia pode constituir-se enquanto uma força social isto é, enquanto capaz de contribuir para a conformação e para o movimento de uma formação social.

Mesmo com a adoção da proposta de Lukács e outros autores a ele próximos, não é possível deixar de mencionar algumas consequências da consideração da questão da ideologia a partir do referencial aqui definido, marcando nossa posição em relação à teoria de Marx - 0 que procuraremos fazer brevemente, a final deste artigo. Antes, tem espaço a apresentação da dinâmica que consideramos típica do fenômeno ideológico e que fora por nós sintetizada sob a denominação linguagem da evidência - enquanto resultado e, ao mesmo tempo, processo pelo qual uma ideologia se efetiva. A elucidação da dinâmica da ideologia nesses moldes específicos só se dá, por sua vez, através de sua prévia caracterização não a partir de algum conteúdo ou traço peculiar que suas manifestações venham a ter, mas sim a partir de sua função social. Em outras palavras, os aspectos relativos à verdade ou à falsidade da representação levada a cabo pela ideologia, assim como o seu caráter possivelmente retrógrado, conservador, progressista ou libertário, estão subordinados à necessidade de que ela faça frente a certos conflitos que inevitavelmente emergem em meio a uma formação social.

Sem dúvida, também tal caracterização da ideologia a partir de sua função social requer uma anterior explanação acerca de seus fundamentos. Com isso, distinguimos, à luz da interpretação de Lukács, a existência de um fio condutor na e da obra marxiana, a balizar o modo como tal sistema teórico está organizado - a saber, entendemos o trabalho ou a atividade humana como fundamento de toda a vida social. Nesse sentido, atingem-nos por decorrência a não dicotomia entre realidade objetiva e subjetividade, a vinculação entre aspectos ordinários e aspectos complexos da reprodução social e o mútuo desenvolvimento do indivíduo 
e do ser social - elementos que se tornam, então, ponto de partida para a concepção de ideologia aqui defendida.

\section{PRIMEIROS PASSOS PARA A COMPREENSÃO DA IDEOLOGIA EM MARX: A IMPORTÂNCIA DO ELEMENTO SUBJETIVO E ALGUMAS CONSEQUÊNCIAS}

Quando Marx discute a relação entre o ser humano e 0 meio que 0 circunda, sinaliza para a importância crucial da consciência. Nas Teses sobre Feuerbach, explicita diretamente sua diferença em relação a um materialismo de tipo vulgar, representado na figura do próprio Ludwig Feuerbach, em função da desconsideração da dimensão subjetiva por parte deste - já que, em Feuerbach, o objeto é concebido de forma isolada (FEUERBACH, 2007, p. 41-42). Ainda, também há, nas mesmas Teses, a crítica de Marx aos idealistas, em especial a Hegel, pois aponta 0 quanto "o aspecto ativo foi desenvolvido de maneira abstrata pelo idealismo” (MARX, 1999, p. 11) - o que se vincula, por sua vez, a uma hipertrofia da especulação, base para a equivocada consideração da consciência enquanto princípio movente da história.

Marx opõe-se veementemente a esta imputação de um movimento lógico à história e coloca que, ao contrário, a mesma diz respeito aos movimentos práticos dos seres humanos (MARX; ENGELS, 2007, p. 32-33). Todavia, esclarece que a atuação prática sobre a realidade objetiva só ocorre a partir de uma préformulação ideal da mesma, a qual tem lugar na consciência do agente (MARX, 1985, p. 149-150) - esta última emergente e conformada a partir do próprio imperativo de atuar sobre 0 mundo.

A grande questão, então, é que a realidade objetiva aparece como o ponto de partida efetivo para o desenvolvimento social e histórico e para a compreensão do mesmo. Porém, ela só pode ser elucidada através de sua interrelação com a subjetividade, a qual exerce um papel decisivo - já que a consciência então se configura como um guia da e para a ação. Com isso, se antes eram visualizadas em oposição ou mesmo em contradição, com Marx, realidade objetiva e subjetividade passam a ser compreendidas em sua necessária relação não dicotômica - onde se entende o lugar de cada uma a partir da interação entre ambas. 0 materialismo marxiano, assim, localiza na realidade objetiva a determinação fundamental, sem deixar de atribuir aos produtos da consciência uma atuação não só possível, mas, sobretudo, necessária. 
A relação não dicotômica entre realidade objetiva e subjetividade confirma a impossibilidade de uma teleologia regente da história, dando destaque, ao contrário, a espaço dado às decisões alternativas existentes perante o sujeito que age. É 0 que se depreende da célebre frase, "Os homens fazem sua própria história, mas não a fazem como querem” (MARX, 1997a, p. 21), de modo que, assim, é plausível que se fale de um ato de responder (LUKÁCS, 2009) às condições objetivas que apresentam as possibilidades para a ação.

A confrontação com tais condições objetivas, por sua vez, se apresenta como muito mais do que um momento pontual e isolado. Na verdade, a mediação, a regulação e o controle incessantes da natureza pelo ser humano forjam um cenário cada vez mais intrincado e complexo, com contornos cada vez mais coletivos e, por isso, sociais. Nos termos de Marx e Engels (2007, p. 87), a condição fundamental de toda a história é a própria satisfação de necessidades ordinárias, mas a partir daí organiza-se "uma forma determinada de sua atividade, uma forma determinada de exteriorizar sua vida, um determinado modo de vida desses indivíduos". Destaca-se, assim, um fluxo peculiar internamente à produção-reprodução social, onde se entrelaçam os fatos, as ocorrências mais imediatas e concretas da existência humana e os seus produtos mais complexos e abstratos.

Nesse fluxo, modificam-se continuamente o objeto e o meio no qual se age, mas também aquele ou aquela em atividade (MARX, 1985, p. 149). Cada transformação proporciona, ainda, um alargamento das possibilidades de ação e das possibilidades de conhecimento - em suma, uma expansão do horizonte geral disponível. Nesse sentido, deve-se perceber que o desenvolvimento da base material traz invariavelmente consigo o desenvolvimento daquele ser que é social, o qual, por sua vez, se revela necessariamente no desenvolvimento do indivíduo. A manifestação de tal indivíduo - "mesmo que ela não apareça na forma imediata de uma manifestação comunitária de vida, realizada simultaneamente com outros - é, por isso, uma externação e confirmação da vida social” (MARX, 2004, p. 107, grifo da edição original).

A indissociabilidade entre vida individual e vida genérica não significa, porém, a inexistência de diferenças entre ambas - ou mesmo a existência de uma simples diferença de grau entre uma e outra. Há um contínuo movimento de conformação do mundo social pelos sujeitos, onde "A tradição de todas as gerações mortas oprime como um pesadelo o cérebro dos vivos" (MARX, 1997a, p. 21), a tal ponto que, finalmente, há uma transcendência do tempo da humanidade em relação ao tempo dos indivíduos (MÉSZÁROS, 2007, p. 35). Em 
correlação ao referido alargamento das possibilidades de ação e das possibilidades de conhecimento, isso implica o desenvolvimento de múltiplas e distintas necessidades, as quais expõem que a indissociabilidade entre vida individual $\mathrm{e}$ vida genérica também não significa a impossibilidade de manifestação de valores variados, dissonantes ou até mesmo contraditórios entre si no bojo do desenvolvimento social.

$\mathrm{Na}$ verdade, perante as decisões alternativas às quais se deve responder, a ação humana constitui-se e desenrola-se segundo certo valor ou complexo de valores, que, advindos das diferentes necessidades continuamente emergentes, expressam, sob muitas mediações, as relações sociais que os conformaram. Nesse sentido, subsistem em tais valores ou complexos de valores as determinações oriundas dos diferentes grupos e/ou classes sociais existentes nas várias formações sociais ao longo da história, de modo que "o próprio conteúdo axiológico desse indivíduo manifestar-se-á antes de mais nada no conteúdo axiológico da comunidade por ele escolhida" (HELLER, 2008, p. 109, grifo do autor).

A partir daí, é preciso ressaltar que, em Marx, o mútuo desenvolvimento do indivíduo e do ser social não exclui, portanto, a existência de particularidades, as quais consolidam as próprias relações sociais, na composição concreta de uma dada formação social. De fato, toda a obra marxiana indica extensamente que, se 0 movimento da história pode ser sintetizado abstratamente na interação entre forças produtivas e relações de produção (MARX; ENGELS, 2007) ${ }^{2}$, o seu curso só pode ocorrer através do confronto entre as distintas classes sociais, entendidas por vezes de forma ampla na letra de Marx (MARX; ENGELS, 1998, p. 40), a expressarem, então, a inevitável forma coletiva que os sujeitos adquirem ao decorrer histórico.

${ }^{2}$ Com a menção ao texto d'A ideologia alemã, convém um breve esclarecimento: nesta obra, Marx, juntamente com Engels, não fala em relações de produção e sim em intercâmbio. Neste momento, intercâmbio apresenta-se de forma bastante ampla e difusa, indicando 0 estabelecimento de uma mutualidade entre ser humano e natureza, entre diferentes grupos sociais, entre distintas nações etc., dentre os quais se estabelece uma espécie de dependência recíproca. Posteriormente, esta ideia ganha uma maior determinação, nas obras consideradas "de maturidade", de modo que Marx foca as diversas relações que concorrem para o concreto desenrolar da produção material, a saber: relações de propriedade e relações jurídicas específicas, divisão social do trabalho, uma dada organização política etc. - e então aparece o termo relações de produção. No entanto, é possível afirmar que, mesmo sem ele, já se distingue, n’A ideologia alemã , a fundamentação da história em dois polos interdependentes: as condições objetivas em que produzem os sujeitos e as relações que se estabelecem para tal produção - permitindo-nos, enfim, a adoção do termo relações de produção quando nos referimos a esse importante apontamento presente nesta obra escrita em parceira com Engels. 
Sendo o embate entre as classes e/ou grupos sociais fundamental para a explicação marxiana, certamente 0 é também para a compreensão da caracterização da ideologia e sua dinâmica - a serem consideradas a seguir.

\section{CARACTERIZAÇÃO DA IDEOLOGIA FUNDAMENTADA NO TRABALHO E O CONSEQUENTE DESTAQUE À SUA FUNÇÃO SOCIAL}

Devido ao modo como concebe o trabalho, Marx defende que, para o desenvolvimento da história, não é possível uma interação pontual e isolada dos sujeitos com o meio circundante (MARX; ENGELS, 2007, p. 32-34). Na verdade, a atividade humana desenrola-se continuamente e forja um cenário cada vez mais social, intrincado e complexo, conformando uma totalidade que o próprio sistema teórico marxiano preocupa-se claramente em traduzir. Por contemplar a constituição da produção social na forma de uma totalidade, Marx então enxerga não só uma determinação material que atinge todos os complexos componentes da vida social - mesmo as criações teóricas e formas de consciência - como também a ação interdependente de todos esses complexos entre si (MARX, 1982, p. 14; MARX; ENGELS, 2007, p. 42). De fato, a crescente complexidade do todo orgânico ao longo da história revela cada vez mais claramente a necessária contribuição de criações teórico-espirituais e formas de consciência, comumente tidas como partes da superestrutura - ainda que esta não seja autônoma em relação à base material da qual adveio.

Nesse sentido, para debatermos o que é, o que concerne, como se constitui, quais as possibilidades ou os limites do fenômeno ideológico, não cabe nos limitarmos ao apontamento de que a ideologia é impulsionada a partir da base material de uma formação social. Falar da determinação material da ideologia não é em nada suficiente: é preciso, além disso, elucidar qual é a sua especificidade dentro da referida totalidade e perante as outras formas de consciência que se constituem com a vida social, como, por exemplo, a ciência - considerando, inclusive, 0 alerta acerca das dificuldades que atingiram e ainda atingem a reflexão sobre ideologia dentro do próprio marxismo.

Sendo assim, verificamos que o caráter intrinsecamente social da produção, na atuação invariavelmente coletiva dos sujeitos na reprodução da vida, abre-a para interferências dos diferentes interesses presentes dentro dela - muitas vezes bastante divergentes entre si. Desse modo, com a referida complexidade que marca a totalidade social, emergem e apresentam-se questões, conflitos e impasses, que detêm então potenciais implicações para a organização da 
sociedade em questão - e, logo, com ressonâncias no modo como se conforma a produção. Devido ao fato de que emergem justamente a partir das possibilidades abertas historicamente, não é possível que se determine de antemão os traços e a amplitude de tais conflitos, impasses e questões - a concernirem a aspectos mais existenciais ou mesmo a aspectos mais imediatos da vida. Porém, a impossibilidade de delimitação prévia de seus contornos não anula que sua emergência requisita um elemento regulador, o qual se constitui então enquanto um fator importante na e para sua mediação.

É a ideologia justamente tal elemento regulador, fundamentado na possibilidade de que a consciência é sempre requerida para a efetivação de caminhos abertos pelas condições objetivas. Ela é capaz de atuar nas situações de conflitos, questões e impasses aludidas por ser uma elaboração específica, onde se representam justamente os mais variados aspectos relativos à vida em sociedade. Essas representações, segundo precisam Marx e Engels (2007, p. 93),

[...] são representações, seja sobre sua relação com a natureza, seja sobre suas relações entre si ou sobre sua própria condição natural [...]. É claro que, em todos esses casos, essas representações são uma expressão consciente - real ou ilusória - de suas verdadeiras relações e atividades, de sua produção, de seu intercâmbio, de sua organização social e política.

Relativa às relações dos seres humanos consigo próprio, com outros seres humanos e com 0 ambiente que os cercam, "A ideologia está colocada na esfera da produção intelectual e reflexiva acerca da própria existência humana" (RANIERI, 2003, p. 22). Com tal conteúdo, as representações ideológicas carregam a pretensão de influenciar a vivência social, a maneira como a sociedade como um todo irá se organizar, de modo que seu norte, então, é a produção enquanto um ato social.

Nesse sentido, a ideologia procura atingir a prática dos sujeitos direta ou indiretamente envolvidos na velada ou evidente disputa de interesses. Para tal, ela conforma-se como a tomada de consciência de uma dada situação, como 0 momento ideal que operacionaliza e equaliza a ação a ser empreendida frente a um conflito originado a partir do arranjo social (RANIERI, 2003; VAISMAN, 2009). Inevitavelmente, está então associado à ideologia o atributo de formar a subjetividade humana, visando "todo um campo de reações desejadas (ou não desejadas) em relação a fatos, situações, obrigações, etc. sociais" (LUKÁCS, 1981, p. 25), a moldar, em suma, o comportamento dos sujeitos. 
Todavia, o atributo último não pode ser considerado isoladamente, como dizendo respeito somente à construção de uma dada individualidade por si só. Ao contrário, existe um sentido específico e nada difuso na afirmação de que à ideologia relaciona-se a formação da subjetividade, cuja base está em sua respectiva finalidade de concretizar tendências então consonantes a certos interesses coletivos em disputa, com o fito de imprimir dado contorno à produção social. Por conseguinte, na ideologia está presente uma necessidade objetiva, que vincula à formação da subjetividade uma contribuição necessária para a afirmação ou para a negação da ordem vigente, para a manutenção ou para a mudança dos aspectos e/ou do modo como se organiza a sociedade. Como resultado, revela-se a referida formação da subjetividade vinculada e consonante ao caráter de projeto do qual é inevitavelmente dotada a ideologia - um projeto para a formação social. Acerca deste aspecto, sintetiza Tertulian (2008, p. 73, grifo da edição original): "a ideologia jamais é puro reflexo, mas um projeto e uma justificação"

0 caráter de projeto não deve imputar à ideologia uma intencionalidade manifesta ou mesmo um traço ardiloso. Na verdade, como "um projeto e uma justificação", a ideologia tão somente revela-se enquanto elemento impulsionado por grupos e/ou classes sociais, cuja atuação na produção incita à conformação da completude da ordem social, procurando garantir, através de um específico alinhamento dos sujeitos em atuação, a satisfação de seus respectivos e nem sempre conscientes interesses. Por isso, tal caráter torna claro, finalmente, 0 aspecto de luta apontado por Marx como característico das ideologias, no célebre Prefácio de 1859 de Para a crítica da economia política. Devido à luta, é possível notar a imanente tensão oriunda da disputa pelos sujeitos, em meio aos possíveis rumos então abertos à sociedade:

[...] é necessário distinguir sempre entre a transformação material das condições econômicas de produção, que pode ser objeto de rigorosa verificação da ciência natural, $e$ as formas jurídicas, políticas, religiosas, artísticas ou filosóficas, em resumo, as formas ideológicas pelas quais os homens tomam consciência desse conflito e o conduzem até o fim (MARX, 1982, p. 25, grifo nosso).

A partir dos aspectos levantados, torna-se frágil a proposição de que a ideologia deve, necessariamente, apresentar-se enquanto uma falsa consciência ou uma consciência invertida - em qualquer uma de suas leituras. Certamente, destaca-se dentro da obra de Marx a ideologia dominante, baseada na mistificação ou na ilusão e propagada com fins de dominação e subordinação, devido ao 
controle exercido pela classe dominante sobre a produção e distribuição das ideias de seu tempo histórico (MARX; ENGELS, 2007, p. 47). Porém, se pensarmos na determinação material desta específica forma de consciência e sua impossibilidade de autonomia, que encaminha os sujeitos atuantes em uma sociedade de acordo com certas tendências e necessidades objetivas advindas da produção social, concebemos como o menos importante a associação da forma de representação aqui tratada à específica posição da classe dominante política e economicamente, ao seu caráter prático-político, como retrógrado, conservador, progressista, libertário etc., ou então à sua dimensão gnosiológica, como correspondente ou não ao conteúdo da realidade objetiva. Conforme esclarece Mészáros (2008, p. 11, grifo do autor): "A questão da "falsa consciência" é um momento subordinado dessa consciência prática circunscrita pela época e, como tal, sujeita a uma multiplicidade de condições especificadoras, que devem ser avaliadas concretamente em seu próprio cenário".

0 aspecto de "todo orgânico" típico da vida social, indissociável da inexistência de uma teleologia metafísica internamente a ela, indica a necessidade de, antes de tudo, avaliar a atuação dos produtos teóricos e formas de consciência então emergentes - já que os mesmos encaminham as alternativas abertas aos sujeitos. Com isso, a determinação fundamental da ideologia está em sua capacidade de incidência nos conflitos de cunho social - sobre a qual discorremos até o momento. Consequentemente, todos os traços imediatos de uma possível representação ideológica são secundários, embora ainda importantes, frente à sua função social - o que, enfim, lhe possibilitará ser ou não uma ideologia: "É a função social que decide se alguma coisa se torna ou não ideologia, sobre este fato a gnosiologia, pela sua natureza, nada tem a dizer" (LUKÁCS, 1981, p. 118).

Falar em função social não é, de forma alguma, engessar a maneira pela qual se manifesta uma ideologia ou presumir certo desenho a priori de dada formação social. Ao contrário, é buscar tão somente respeitar a inserção deste elemento da vida social na complexa articulação das condições objetivas, de modo, ainda, a congregar, em uma forma sintética, certos atributos importantes do fenômeno ideológico - a saber, sua determinação pela base material, sua intervenção nos conflitos de cunho social, sua (auto)construção enquanto momento ideal da prática dos homens e a conformação destes de acordo com um projeto relacionado a essa mesma ideologia (SILVA, 2012, p. 87).

Como se pode notar, a caracterização a partir da função social abre possibilidade para apreendermos os múltiplos contornos da ideologia - em consonância à multiplicidade de conflitos, impasses e questões aos quais deve 
potencialmente fazer frente. Ainda assim, não se apaga o papel muito específico que ela detém. Desse modo, as variadas formas de manifestação possíveis deste fenômeno não devem levar à aproximação da ideologia a um conjunto de ideias ou então a uma concepção de mundo. Embora muitos autores assim a qualifiquem, acreditamos que tal aproximação não só retira sua especificidade frente às outras formas de consciência, como também obscurece um aspecto fundamental: ideologia não é um atributo perene de uma dada representação. Diferentemente, ela está sujeita ao movimento e às contradições da reprodução social e, desse modo, ao invés de ser encarada como uma elaboração fixa, deve ser pensada antes enquanto um processo em movimento. Nesse sentido, uma formulação ideal não necessariamente emerge como ideologia, mas, se não o faz, pode assim tornar-se ou também deixar de sê-lo - de acordo com as condições objetivas que a cercam.

A consideração deste último aspecto auxilia a compreensão da dinâmica típica da ideologia, como uma força capaz de influenciar o movimento de uma dada formação social. Antes da exposição de tal dinâmica, convém sublinhar que, voltando-se para os conflitos, a ideologia só pode efetivar-se caso seja de fato incorporada pelos sujeitos, os quais então traduzem o momento ideal no qual ela se configura em prática. Deve ela então voltar-se para as ações dos mesmos, considerando que estas podem ser influenciadas.

Nesse sentido, a ideologia tem sua ancoragem nas representações dos atos de exteriorização dos sujeitos (TERTULIAN, 2008, p. 70) e, por isso, seu caráter é, em síntese, antropocêntrico e antropomorfizante. Mais especificamente, a ideologia tem sua origem na atividade e na produção social, assim como todos os complexos típicos da superestrutura. Porém, em seu desenvolvimento, deve manter "viva" a correspondência à condição e aos atos concretos humanos, sob pena de não lograr êxito - ao contrário do que ocorre com outros produtos teórico-espirituais, como, por exemplo, a já citada ciência, cuja perpetuação ocorre justamente a partir da desvinculação de seu enunciado de algum ato humano concreto.

Como consequência de sua função social de dirimir conflitos, a associação mais eminente e direta com a existência humana é então outra peculiaridade do fenômeno ideológico. Tal caráter antropocêntrico e antropomorfizante completa, enfim, nossa caracterização geral da ideologia e abre as portas para a compreensão de seu peculiar modus operandi. 


\section{COMO A IDEOLOGIA PROFERE UMA LINGUAGEM DA EVDÊNCIA}

As limitações e delimitações postas pelas condições objetivas tornam bastante complexa a análise da dinâmica da ideologia - tanto porque permitem a variedade de manifestações do fenômeno quanto por não 0 dotarem de um conteúdo fixo. Assim, já que a forma de consciência em questão emerge devido às "exigências objetivas do processo de reprodução social” (MÉSZÁROS, 2004, p. 472), cabe compreendê-la considerando seu papel frente a tais exigências e seu peculiar fluxo de interiorização e exteriorização - tendo em mente que a ideologia efetiva-se somente quando os sujeitos a internalizam e a traduzem na forma de ação, nos momentos de conflitos, questões e impasses sociais.

Certamente, ao não nos determos em nenhuma manifestação específica do fenômeno ideológico, só é possível desvelarmos o peculiar fluxo de interiorização e exteriorização citado em suas linhas mais gerais, como consequência do que fora levantado no item anterior - e justamente por isso é tão importante demarcar as diferenças da ideologia em relação a outras formas de consciência e produtos teórico-espirituais.

Posto 0 alerta, pode-se dizer: antes de tudo, a função social e o consequente caráter antropocêntrico e antropomorfizante indicam que, para aqueles e aquelas aos quais se direciona, a ideologia deve "fazer sentido", expressar-se com um tom de "verdade". Conforme alerta Lukács (1981, p. 10, grifo nosso),

[...] os interesses são, decerto, por força das coisas determinados pela estrutura social, mas que tais determinações podem se tornar o motor da práxis somente quando os bomens singulares vivam estes mesmos interesses como seus próprios interesses, e tendam a afirmá-los no quadro das relações para eles vitais com outros bomens.

Em outras palavras, por realizar-se com e através da prática eminentemente direcionada a conflitos, é crucial que a ideologia atinja os sujeitos individualmente, apresentando-se enquanto uma representação das próprias relações, condição e existência destes mesmos sujeitos - ainda que sob a influência da mistificação ou da ilusão. Sem dúvida, esta última observação não nos deve levar à confusão da ideologia com uma elucubração arbitrária de um único indivíduo - o que é também inconciliável com sua respectiva função social. Ao contrário, no momento devem-se retomar não só o fato de que a ideologia traz consigo um determinado projeto de sociedade, exprimindo interesses coletivos em 
disputa, mas também a dimensão social constituinte de cada indivíduo, que faz nele subsistir o ser genérico, inevitavelmente mediado pelas determinações do(s) grupo(s) e/ou classe social em que se insere tal indivíduo.

Consequentemente, a elucidação da ideologia como uma força social, na revelação de sua influência sobre 0 decorrer da história por meio da prática dos sujeitos, deve conjugar limites e disposições gerais de caráter objetivo impostos aos contornos da representação tipicamente ideológica e aspectos da condição de individualidade. Confrontando as possibilidades históricas então existentes, a dinâmica da ideologia compõe-se, assim, de diversos impulsos, intimamente complementares uns aos outros - e, logo, separáveis apenas analiticamente.

Para expor, então, os diferentes níveis desta única análise, convém recordar que, como uma forma de consciência, a ideologia é uma maneira pela qual se apreende o mundo. Nesse sentido, deve ela inevitavelmente compor um quadro da realidade social no qual sejam distinguidos os determinantes que dão os contornos desta. No caso, a construção do reflexo, entendido aqui como tal representação ideal da realidade social, responde aos interesses coletivos em jogo e, por isso, uma ideologia não precisa necessariamente prover uma imagem fidedigna ou "correta". Diferentemente, cabe a ela somente distinguir algum ou alguns traços, aspectos, elementos e fatores presentes na realidade social que tenham afinidade com algum ou alguns dos interesses em voga - ainda que isso não seja feito de forma patente e nem mesmo levado a cabo de modo francamente intencional. A preocupação é tão somente uma explicação plausível, pela qual seja possível projetar um decurso da vida social então desejável (MÉSZÁROS, 2004, p. $69)^{3}$.

Mesmo que se projete um caminho para toda a coletividade, a necessidade de compatibilidade com os sujeitos antes mencionada indica, por sua vez, que a plausibilidade proclamada por uma representação ideológica não pode carecer da correspondência, em maior ou menor grau, com as condições cotidianamente vivenciadas por eles. Com isso, a resposta composta pela ideologia deve remeter ou, ao menos, tangenciar vivências, relações e fatos mais imediatos -

\footnotetext{
${ }^{3}$ Sem dúvida, quando se move a partir do anseio de modificar a ordem social, uma ideologia tem na elucidação verídica das condições materiais e das relações sociais vigentes uma grande aliada diferente do que ocorre com a ideologia dominante. Ou seja, como esta visa somente à manutenção da ordem social, mobiliza invariavelmente a mistificação e a ilusão para a definição de certos traços, aspectos, elementos e fatores a ela importantes. Ainda assim, com ou sem mistificação, permanece a necessidade de que a ideologia prova um retrato razoável da realidade e/ou conjuntura em questão.
} 
relacionando-os e/ou moldando-os de acordo com o projeto de sociedade que carrega. Encontra-se aí uma possibilidade de que a ideologia seja reconhecida pelos sujeitos, de que ela faça sentido frente a potenciais outras respostas. Além disso, sobre o cotidiano repousa também sua própria efetividade, na equalização dos conflitos por ventura existentes, pois, no reconhecimento de que o desenrolar da história não se dá de maneira abstrata, a vida cotidiana deve ser vista não só como 0 ponto de partida, mas também como o ponto de chegada da ideologia: dela são retirados os aspectos a serem mobilizados, as respostas a serem sintetizadas, e a ela, finalmente, devem estas retornar, para que sejam realmente levadas a cabo pelos sujeitos (FREDERICO, 2000, p. 303; LUKÁCS, 1981, p. 110).

É importante esclarecer que não entendemos vida cotidiana através de uma pretensa escala, dentro da qual conceberíamos, por exemplo, microrelações, microdecisões, microcausas, microconsequências, etc. Ao contrário, a vida cotidiana é vista aqui como um momento específico da produção e reprodução da vida e, por isso, erige um estado específico da consciência, interligado e interrelacionado a um modo também específico de se desenvolver a atividade prática. Nomeadamente, considerando a importância da contínua satisfação das necessidades humanas (MARX; ENGELS, 2007, p. 33), é característica da vida cotidiana a espontaneidade e 0 imediatismo - consonantes à impossibilidade de que se reflita sempre, em todos os momentos e em todas as ocasiões, acerca da completude da totalidade social (HELLER, 2008, p. 47).

Tanto a espontaneidade quanto o imediatismo citados auxiliam uma apreensão cada vez mais sintética dos determinantes fundamentais da realidade social - a qual, como sabemos, é "uma concentração [...] de muitas determinações” (MARX, 1997b, p. 9). Com a simplificação dos determinantes, 0 que se tem, por consequência, é a tendência ao fortalecimento do vínculo entre 0 reflexo gerado e a atitude prática daí derivada, na medida em que a posição de finalidade gerada praticamente passa de alternativa à decisão óbvia, no obscurecimento de outras possibilidades existentes. Para a ideologia, cujo foco maior é justamente a prática, a formulação de uma síntese simplificadora significa então uma maior inserção internamente à formação social, com uma força crescente em função de sua contínua concretização. Nas palavras de Lukács (1981, p. 116): "A ontologia da vida cotidiana, como simplifica e muitas vezes vulgariza as partes da ideologia que nela desembocam [...], possui assim também uma tendência à síntese: ambas as coisas por reforçar a função ideológica, a guia imediata da prática." 
Com isso, o cotidiano é lócus favorável para a encorpadura da ideologia. Mais especificamente, através do fornecimento dos elementos mais fundamentais a comporem a resposta trazida aos conflitos e da facilidade que apresenta à sua recepção, o cotidiano permite uma maior identificação da ideologia pelos sujeitos, como uma elaboração que a eles faz sentido por retratar sua condição e, ainda, por encontrar apoio para seu desenrolar na realidade - ressaltando, inclusive, que toda a construção feita pela ideologia não deve estar deslocada de alguma possibilidade objetiva ou tendência histórica vigente ao momento ${ }^{4}$.

Nesse sentido, não se pode esquecer a existência de um direcionamento na ideologia - mesmo que não estruturado de forma patente ou discricionária. A prática por ela informada está, assim, repleta de valores ou complexos de valores, de modo que, ao propagá-los, os sujeitos inevitavelmente se projetam e se interligam a uma certa medida do ser social existente àquele momento histórico também nem sempre de forma patente. Considerando a necessidade de dirimir os conflitos sociais e, por isso, alinhar a subjetividade a um dado projeto de sociedade, a ideologia então estimula de modo peculiar 0 âmbito genérico da existência dos indivíduos visados. Em outras palavras, com ela é trazida também uma imagem de ser coletivo, com parâmetros, tácitos ou não, dentro dos quais se deve agir e, logo, à qual se deve corresponder.

Consequentemente, a ideologia não deixa de promover uma identidade entre os sujeitos que ela atinge. Por um lado, a forjada identidade permite 0 reconhecimento mais imediato daquela resposta trazida pela ideologia como própria pelo indivíduo, sem se retirar do âmbito do cotidiano, mas também eleva, de modo muito importante, a mesma resposta ao patamar de dever ser social necessário para a resolução dos conflitos, impasses e questões também sociais. Juntamente ao sentido que a resposta em questão ganha, advém então uma maior "validade naquela norma de conduta" (IASI, 2006, p. 253), por ser partilhada com e reconhecida igualmente através dos demais. Por outro lado, tal identidade promove complementarmente uma força agregadora, numa costura dos indivíduos singulares em um sujeito coletivo, e, desse modo, fortalece ainda mais a resposta em foco, encaminhando-a para a concretização e demarcando-a frente a outras posições e, eventualmente, outros sujeitos coletivos (MÉSZÁROS, 2008, p.

\footnotetext{
${ }^{4}$ Indicar tal importância do cotidiano para a ideologia não significa restringi-la aí, afastando-a de outros complexos presentes na vida social, pois nem o cotidiano é algo fixo - e sim tão somente um momento da produção e reprodução social, cujas mediações por vezes não são apreensíveis aos sujeitos - e nem é possível conceber, de acordo com Marx, um isolamento dos componentes da totalidade social. Na verdade, o que se procura é apenas ressaltar que o poder da ideologia perante os conflitos depende do seu entrelaçamento à reprodução ordinária da vida.
} 
12). Enfim, através de ambos os lados vê-se uma tendência a tornar a alternativa e o caminho aberto com dada ideologia sempre mais próximos dos sujeitos.

Entretanto, reconhece-se que a ideologia constitui e se constitui em uma tensão entre indivíduo singular e coletividade e, logo, confirma-se que o traço antropocêntrico e antropomorfizante não exclui a concepção da ideologia como produto tipicamente social. Ao contrário, o fenômeno ideológico é elaboração de uma coletividade e, devido ao caráter dos interesses visados, procura atingir os indivíduos, mas sempre de modo a equalizar as diferentes manifestações individuais ao sentido social almejado. Com este fito, ao estabelecer e estimular certos valores à prática humana, inevitavelmente erige certos significados, que passam a influenciar a apreensão da natureza, das relações, de si - em suma, sua subjetividade (MÉSZÁROS, 2007, p. 34).

Se a consequente exteriorização encontra respaldo, real ou ilusório, nas condições objetivas que a cercam, na satisfação das necessidades e/ou interesses que a movem, a ideologia é capaz então de confirmar-se, cada vez mais se sedimentando, sendo interiorizada pelos sujeitos. Com isso, termina forjando um vínculo com aqueles e aquelas que a proferem, ativando a dimensão afetiva que cerca as construções e os valores humanos em geral, fundamentada no caráter padecente do ser social - o qual é conectado materialmente com os produtos que cria (MARX, 2004, p. 128; MÉSZÁROS, 2006, p. 181).

É a dimensão afetiva potencialmente existente que então torna o confronto a uma ideologia deveras difícil. Na medida em que se trata de uma consciência prática do conflito social (MÉSZÁROS, 2008), a questão não é somente a modificação das representações, mas do próprio fluxo de interiorização e exteriorização aludido e, logo, de todas as condições que sustentam a profunda inserção e persistência da ideologia nos sujeitos. É por isso que, inclusive, a adoção e a filiação a uma dada ideologia não é uma questão de esclarecimento, como somente uma mera escolha ou inclinação voluntariosa (SILVA, 2012, p. 170-171).

A partir de todos os aspectos levantados, pode-se finalmente afirmar que a força da ideologia advém do que optamos por chamar de linguagem da evidência (SILVA, 2012). Em outras palavras, através de todos os impulsos citados, vivenciase objetiva e subjetivamente o cenário apresentado com a ideologia, à medida que se experimenta, nas mais diversas relações com o meio e com aqueles e aquelas ao redor, as indicações transmitidas claramente ou não por tal complexo da vida social. A ideologia é, assim, a justificativa para o (seu) mundo, mas essa mesma justificativa, por sua vez, não exige para si argumento - quando fundida, sem 
dúvida, às vivências compartilhadas, no respeito às condições objetivas abertas. Desse modo, a síntese de todos os aspectos trabalhados, a saber, vida cotidiana, valor, generalização, força agregadora, imagem de ser coletivo, dimensão afetiva na forma da própria linguagem da evidência -, é tanto o processo quanto 0 próprio resultado pelos quais se consolida uma ideologia.

\section{CONSIDERAÇÕES FINAIS}

Devido à ausência de sistematização da concepção de ideologia por Marx, assim como à extensão das polêmicas que a envolvem, mantivemo-nos num alto nível de abstração, na opção de falar em função social da ideologia e traçar os contornos deste fenômeno segundo os moldes de uma categoria geral perspectiva esta aventada pelo próprio Marx (1997b), que por diversas vezes assim desenvolveu suas reflexões. Como a categoria geral expressa uma gama de características próprias a um dado fenômeno, revelando seus potenciais delineamentos quando à concretização histórica, ela é muito útil na distinção de suas diferenças frente a outros fenômenos e complexos da vida social. Porém, embora instrumento válido, a categoria geral não é capaz de esgotar todos os traços da realidade - somente apreensíveis à análise concreta da situação concreta - e, nesse sentido, não pode ser oposta à avaliação de manifestações particulares da ideologia, as quais certamente enriquecem ou enriqueceriam as indicações gerais.

É importante sublinhar que esses dois âmbitos de análise não se excluem embora por vezes possam, como aqui foi feito, ser abordados separadamente, a depender do escopo adotado. Sem isso em mente, é possível que, de maneira equivocada, se pense a análise da ideologia através do modo como atinge individualmente os sujeitos contraposta à explicação através dos grupos e/ou classes sociais em disputa. De fato, pontuamos mais de uma vez que 0 fundamento do fenômeno ideológico está na inevitável emergência de distintas propostas para o desenvolvimento social, levadas a cabo por grupos e/ou classes sociais. Todavia, tendo como questão fundamental não a definição ou a mera caracterização da ideologia e sim os contornos de seu peculiar modus operandi descolado de qualquer manifestação específica, em sua generalidade, fez-se necessário o foco na dimensão do indivíduo, do sujeito, respeitando um aspecto saliente do fenômeno ideológico quando visto sem a concorrência de certas particularidades históricas - a saber, seu caráter antropocêntrico e antropomorfizante. 
Nesse momento, é preciso então relembrar que, conforme apontamos no início, quanto ao debate de um elemento tão controverso, abre-se inevitavelmente uma discussão acerca da obra de Marx. Para a análise da ideologia, foi necessário extrapolar o conteúdo isolado dos escritos marxianos, lançando-se ao seu sistema teórico como um todo e, após o estudo do fenômeno em questão, as conclusões alcançadas irresistivelmente nos remetem de volta ao âmbito da reflexão acerca da orientação ampla da qual é dotada a teoria marxiana. Defendemos, por conseguinte, tanto a impossibilidade de uma ruptura entre jovem e velho Marx quanto a existência de uma perspectiva humanista a pautar seus escritos. Com isso, embora alguns autores reivindiquem justamente o conceito de ideologia como um dos exemplos da mudança de terreno - ou problemática empreendida por Marx (ALTHUSSER, 1979), nossa exposição procurou mostrar que, ao contrário, tal conceito confirma a unidade que pauta sua obra.

Percebemos que o conceito de ideologia nos textos marxianos emerge com vistas a revelar a complexidade da reprodução social, a qual funciona como um todo orgânico, numa influência recíproca entre seus elementos. Nesse cenário, as proposições de Marx relativas ao modo como se desenvolve a atividade prática humana, enquanto uma protoforma de todas as outras atividades caracteristicamente sociais, são capazes de apresentar as amplas e potencialmente variadas conformações dos elementos constituintes da vida social - os quais nem derivam mecanicamente das condições materiais de onde emergem e nem se manifestam sob o manto de uma estrutura abstrata que os envolve. Caso se tenha em conta o que aventou Marx no início de seus estudos críticos a Hegel, aos jovens hegelianos de esquerda e aos economistas políticos, acerca da não dicotomia entre realidade objetiva e subjetividade, tem-se igualmente a possibilidade de revelar a ideologia de modo concreto e em seus sentidos potencialmente diversos.

Considerando a específica contribuição à reprodução social, vê-se que a ideologia vincula-se ao desenvolvimento dos seres humanos - ela se localiza ativamente em meio à complexificação da relação entre indivíduo e gênero humano, sendo, ao mesmo tempo, produto de tal complexificação. Por consequência, somos levados a conceber que "também na teoria da ideologia se exprime o princípio fundamental de Marx, segundo o qual para o homem a raiz é o próprio homem" (LUKÁCS, 1981, p. 108). Ou seja, ao longo da obra marxiana, visualiza-se a preocupação em considerar homem/mulher em sua forma concreta, inevitavelmente perpassados por inúmeras determinações e particularidades, fora de modelos abstratos e longe de quaisquer explicações ou atribuições deles dissociadas, supra-históricos. De fundo, revela-se uma concepção que preza e valoriza sua capacidade de autoformação, no zelo de que homem e mulher 
concretos são resultados do processo histórico. Consequentemente, subsiste uma importância teórica e prática do humanismo, que, em Marx, volta-se então para a real possibilidade de transformação social - para a qual a ideologia pode, enfim, certamente contribuir.

\section{REFERÊNCIAS}

ALTHUSSER, Louis. A favor de Marx. Rio de Janeiro: Zahar, 1979.

ALTHUSSER, Louis. Sobre a reprodução. Petrópolis: Vozes, 1999.

FEUERBACH, Ludwig. A essência do cristianismo. Petrópolis: Vozes, 2007.

FREDERICO, Celso. Cotidiano e arte em Lukács. Estudos Avançados, São Paulo, v. 14, n.40, p. 299-308, 2000.

GRAMSCI, Antonio. Cadernos do cárcere. Rio de Janeiro: Civilização Brasileira, 1999.

HELLER, Agnes. O cotidiano e a história. São Paulo: Paz e Terra, 2008.

IASI, Mauro Luis. As metamorfoses da consciência de classe: o PT entre a negação e o consentimento. São Paulo: Expressão Popular, 2006.

LUKÁCS, György. Il problema dell'ideologia. Tradução de Ester Vaisman. In: LUKÁCS, György. L'ontologia dell'essere sociale. Roma: Riuniti, 1981. v. 2. Mimeo.

LUKÁCS, György. As bases ontológicas do pensamento e da atividade do homem. In: LUKÁCS, György. 0 jovem Marx e outros escritos de filosofia. Rio de Janeiro: Ed. da UFRJ, 2009. p. 225-245.

MARX, Karl. Manuscritos econômico-filosóficos. São Paulo: Boitempo, 2004.

MARX, Karl. O capital: crítica da economia política: o processo de produção do capital. São Paulo: Nova Cultural, 1985. v. 1, tomo 1.

MARX, Karl. 018 brumário de Luís Bonaparte. In: . O 18 brumário $e$ cartas a Kugelmann. Rio de Janeiro: Paz e Terra, 1997a. p. 10 - 159.

MARX, Karl. O método da economia política. Tradução de Fausto Castilho, edição bilíngüe. Campinas: IFCH/UNICAMP, 1997b.

MARX, Karl. Para a crítica da economia política. In: GIANNOTTI, José Arthur (Org.). Os Economistas: Marx. São Paulo: Abril Cultural, 1982. p. 1-132. 
MARX, Karl. Teses sobre Feuerbach. In: MARX, Karl; ENGELS, Friedrich. $A$ ideologia alemã: I Feuerbach. São Paulo: Hucitec, 1999. p. 10-14; 125-128.

MARX, Karl; ENGELS, Friedrich. A ideologia alemã: crítica da mais recente filosofia alemã em seus representantes Feuerbach, B. Bauer e Stirner, e do socialismo alemão em seus diferentes profetas. São Paulo: Boitempo, 2007. MARX, Karl; ENGELS, Friedrich. Manifesto comunista. São Paulo: Boitempo, 1998.

MÉSZÁROS, István. O poder da ideologia. São Paulo: Boitempo, 2004.

MÉSZÁROS, István. Filosofia, ideologia e ciência social: ensaios de negação e afirmação. São Paulo: Boitempo, 2008.

MÉSZÁROS, István. O desafio e o fardo do tempo bistórico: o socialismo no século XXI. São Paulo: Boitempo, 2007.

RANIERI, Jesus. Sobre o conceito de ideologia. Estudos de Sociologia, Araraquara, v. 7, n. 13/14, p.7-36, 2003.

SILVA, Nara Roberta Molla da. Decifra-me enquanto te devoro: um estudo da ideologia como força social. 2012. 183 f. Dissertação (Mestrado em Sociologia) Universidade Estadual de Campinas, Campinas.

TERTULIAN, Nicolas. 0 conceito de ideologia na ontologia de Lukács. Margem Esquerda, São Paulo, n. 11, p. 70-81, 2008.

VAISMAN, Ester. Lukács et la question de l'idéologie. Cahiers Philosophiques, Paris, n. 119, p. 79-96, 2009. 